\title{
The absolute Gini is a more reliable measure of inequality for time dependent analyses (compared with the relative Gini).
}

\author{
Sanghamitra Bandyopadhyay \\ Queen Mary, University of London
}

1st June 2017

\begin{abstract}
I compare time series properties of relative and absolute Ginis to examine which one is better suited for time dependent analyses. In particular, I model Gini trends as a fractionally integrated process and find that there are more mean-reverting absolute Ginis than relative Ginis suggesting that absolute Ginis may be better suited than relative Ginis for time-dependent analyses. I then undertake an estimation of the inequality-growth relationship using popular panel regression methods and find that the absolute Gini is negatively and significantly associated with growth for most models estimated, but none for the relative Gini. I deduce that from an empirical point of view, the absolute Gini may be a better choice when undertaking time dependent analyses.

Acknowledgment: I am grateful to Hashem Pesaran for useful discussions. I also thank Jan Luksic for excellent research assistance and the British Academy for funds.

Keywords: Relative Gini, Absolute Gini, Fractionally Integrated Processes, Inequality and Growth relationship, Gini coefficient

JEL codes: C32, D63, O11.
\end{abstract}

\section{Introduction}

In recent years an important literature has developed on the dynamics of global inequality over time (Sala-i-Martin 2005, Durlauf et al. 2009). The Gini is widely used as a measure of inequality for measuring trends in inequality. Despite the wide array of inequality measures available (see Atkinson and Brandolini 2004), the social science literature still uses the Gini, which measures income inequality relative to average income/GDP.

This paper will highlight that the absolute Gini may be a better choice as an inequality measure compared with the popularly used relative Gini for time dependent analyses. The problem of using 
relative Ginis in time dependent analyses lies in that income inequality is measured relative to average income. This implies that time trends of relative inequality measures are likely to follow similar trends as that of the underlying income or GDP process which is used to generate them ${ }^{1}$. The practice of using relative inequality measures to gauge inequality has also been criticised by some recent studies (see Atkinson and Brandolini 2004, Bosmans et al. 2014) where they compare the performances of relative, absolute and intermediate measures of inequality, although they do not consider specific concerns about using time trends of relative and absolute inequality measures.

To illustrate this problem I model the time series properties of these measures as a fractionally integrated process and find that there are more countries that have mean-reverting absolute Ginis than relative Ginis. This suggests that absolute Ginis could be more appropriate for time dependent studies. Thereafter I implement an application, where I estimate the inequality and growth relationship using popular panel regression methods, with both relative and absolute Ginis. I find that the models that use absolute Ginis reveal a stable negative relationship between inequality and growth, but not the case for relative Ginis.

\section{Data and trends}

I use data from the World Income Inequality Database (WIID) database (version 3.3) ${ }^{2}$. There are a few difficulties posed by the database in that the Gini series are often not a continuous series based on the same unit of measurement. The data has been carefully separated for each country's estimate of income inequality to ensure that the same unit of measurement applies for the series. While there is data for over 200 countries in the data-base, I can only use data for 30 countries, where mostly high quality data has been selected ${ }^{3}$.

Thereafter I have used real GDP per capita (in constant 2005 PPP-adjusted international dollars from the Penn World Tables 8.1) to generate absolute Ginis using the relationships below. The relative Gini coefficient, $G_{t}$ is given by:

$$
G_{t}=G\left(Y_{t}\right)=\frac{1}{2 n^{2} \mu_{t}} \sum_{i=1}^{n} \sum_{j=1}^{n}\left|y_{i t}-y_{j t}\right|
$$

\footnotetext{
${ }^{1}$ GDPs are well established in the macroeconomic literature to be highly trended (see Henry and Zaffaroni 2002), and this is likely to be passed on to the relative inequality measure. As a result, relative inequality measures may be reflecting the relatively uninteresting trends of the GDP process rather than the true underlying inequality.

${ }^{2}$ There are two estimates of relative Ginis in the database: relative Ginis estimated by United Nations University World Institute for Development Economics Research (UNU WIDER), and those reported by country sources. Results using the UNU WIDER estimates are reported only.

${ }^{3}$ The data available in WIID covers more than 200 countries, for a time range as early as 1890 s for some countries, to recent years. Developed countries, such as G20 countries, have reported units of measurement on several units of income (such as gross, disposable, monetary etc.) and on consumption. The data provided is also classified as high or low quality depending upon the country source. For the purposes of our study, we had to purge both countries and units of measurement which were based on low quality sources, and those which had less than 30 years' data.
} 
where,

$$
\begin{gathered}
Y_{t}=\left(y_{1 t}, y_{2 t}, \ldots, y_{n t}\right), \\
\mu_{t}=\frac{1}{n} \sum_{i=1}^{n} y_{i} .
\end{gathered}
$$

and $y_{i t}$ is the income of individual $i$ at time $t ; Y_{t}$ represents the income distribution across individuals in time period $t$ and $\mu_{t}$ is the mean income of income distribution $Y_{t}$. Equation (1) can be represented as the ratio of two components:

$$
G_{t}=\frac{A_{t}}{\mu_{t}}
$$

where

$$
A_{t}=A\left(Y_{t}\right):=\frac{1}{2 n^{2}} \sum_{i=1}^{n} \sum_{j=1}^{n}\left|y_{i t}-y_{j t}\right| .
$$

is the absolute Gini and equals half the mean difference.

Trends of the absolute and relative Gini plotted in Figure 1 illustrate the problem. The dynamics of inequality deduced from absolute or relative Ginis can be quite different. Not only can the slope of the trends be different, but for cases of Germany, Estonia, Kyrgystan, Spain, Italy, Japan, and the Netherlands the trends are completely reversed. This suggests that absolute and relative measures can yield very different trends in inequality.

This is a concern as the economics and social science literature typically uses the relative Gini index both as regressor and regressand, with mostly no concern about their time series properties. Panel regression methods recommend that the regressors are stationary. I will therefore now examine the time series properties of the relative and absolute Ginis using a fractionally integrated framework.

\section{Modelling Ginis as a fractionally integrated process}

I will now model Gini trends as a fractionally integrated (FI) process. I eschew the use of unit root models, which have been strongly criticised due to their low power ${ }^{4}$. While there exists a developed literature for unit root models, applied finance and macroeconomics prefer the identification of intermediate stages in between stationary and non-stationary processes. This has led to the notion of fractional integration (FI), which allows for intermediate stages in between the two extremes of non-stationarity and stationarity ${ }^{5}$.

\footnotetext{
${ }^{4}$ I have nevertheless estimated standard augmented Dickey Fuller tests, and most cases exhibit non-stationarity.

${ }^{5}$ There is abundant evidence that supports the empirical relevance of FI models in macroeconomics and finance, justified from both a theoretical and applied perspective (Henry and Zaffaroni 2002, Durlauf et al. 2009). The time series literature also notes that conventional procedures for detecting and dating structural changes tend to find spurious breaks, usually in the middle of the sample, when in fact there is only fractional integration in the data (Nunes et al. 1995). Recent empirical evidence also suggests that relative GDP data is well fitted by a fractionally integrated process (Michellacci and Zaffaroni 2000, Mello 2011). Relative Ginis, are similar to relative GDPs, as they are both deflated by the average income value.
} 

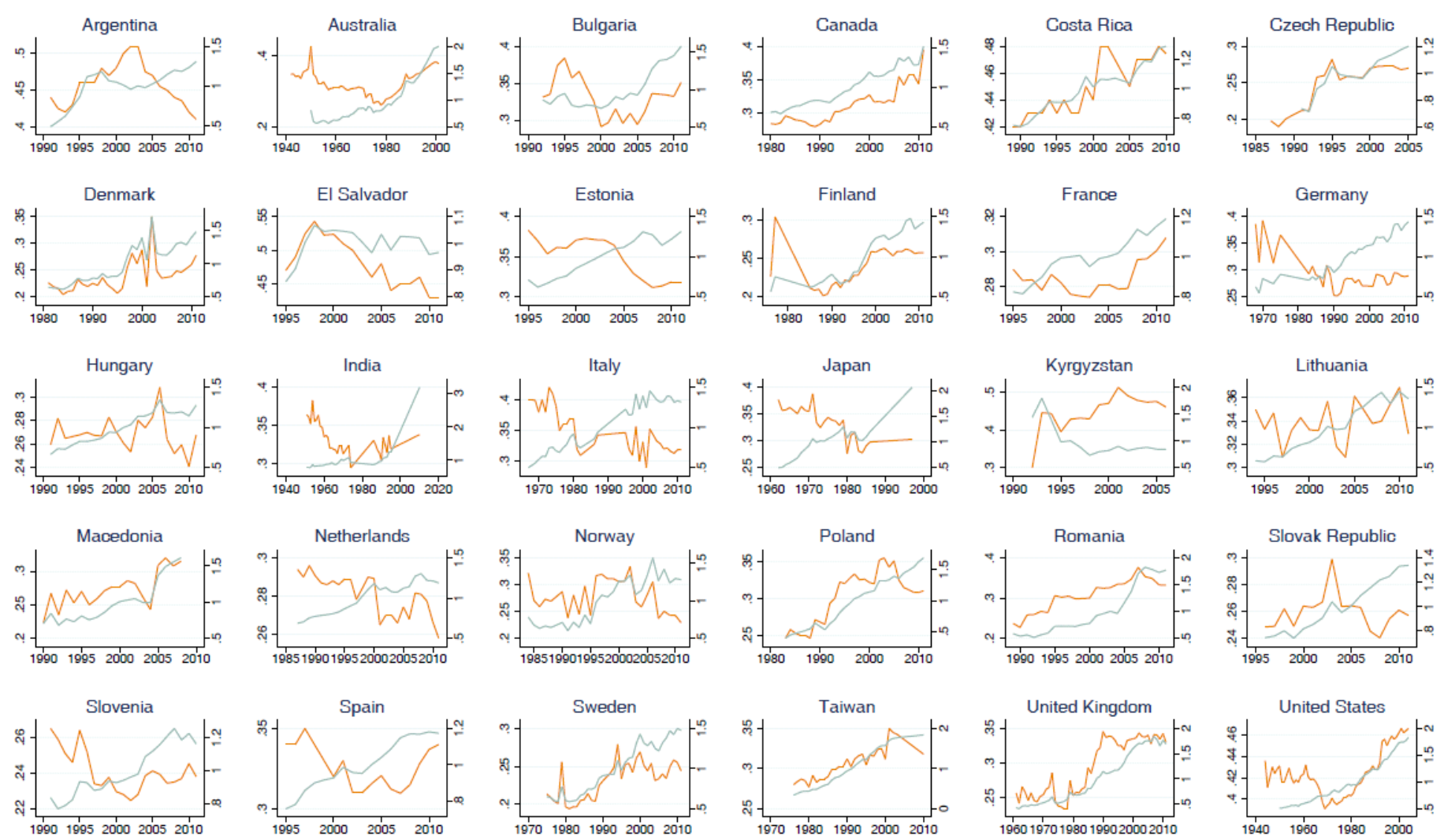

Relative Gini, left Y-axis, \%

Absolute Gini, right $Y$-axis, \% of country average.

Figure 1: Relative and Absolute Gini trends for 30 countries 
I model Ginis as an Autoregressive Fractionally Integrated Moving Average (ARFIMA) process. To fix ideas, let us define an $\operatorname{ARFIMA}(0, d, 0)$ process. Assume a stochastic process for the Gini, $g_{t}$, given by $(1-L)^{d} g_{t}=u_{t}$, where $u_{t}$ is a zero-mean, constant-variance, and serially uncorrelated error term, and $d$ is the parameter of integration, which can assume non integer values. When $d>-1$, the term $(1-L)^{d}$ can be expressed as a binomial expansion $(1-L)^{d}=1-d L+d(d-1) L^{2} / 2 !-d(d-$ 1) $(d-2) L^{3} / 3 !+\ldots$. Invertibility holds when $-1 / 2<d<1 / 2$. Assuming invertibility, the moving average expression is obtained as $y_{t}=\sum_{j=0}^{\infty} \psi_{j} u_{t-j}$, where $\psi_{j}=\Gamma(j+d) / \Gamma(d) \Gamma(j+1)$, and $\Gamma($.$) is$ the gamma function, given by $\Gamma(\alpha)=\int_{0}^{\infty} t^{\alpha-1} e^{-t} d t$

If parameter $d$ lies in the interval $(-0.5,0.5)$ then the above process is deemed stationary; for values $(0.5,1)$, the process is nonstationary, but mean-reverting. Mean reversion requires the cumulative impulse response function $c_{N}=\sum_{j=0}^{N} \psi_{j}, N=0,1,2, .$. , to convergence zero at $\infty .^{6}$

Likewise, it can be shown that if $d<1$, then $c_{\infty}=0$, in other words, then the process is meanreverting. When $d>1$, then $c_{\infty}=\infty$ and when $d=1, c_{\infty}$ is constant and finite, and the process is not mean-reverting.

Table 1 presents results of the estimates of the fractional integration parameter based on methods of Geweke and Porter-Hudak $(1983)^{7}$. For the relative Gini I find that the estimates of $d$ lie in the stationary region for 4 cases (Hungary, Lithuania, Macedonia and the Netherlands) and 6 cases in mean-reverting region (Costa Rica, Denmark, Japan, Norway, Sweden and United Kingdom), out of 30 countries.

For the absolute Gini, estimates of $d$ lie in the stationary region for 1 case (Czech Republic) and 11 cases in mean-reverting region (Argentina, Costa Rica, Denmark, El Salvador, France, Germany, India, Italy, Kyrgystan, Spain and the United States), out of 30 countries.

The findings therefore suggest some mean-reversion in relative Ginis, but many more for the absolute Ginis. This implies that while the absolute Ginis are not stationary, they may be the more appropriate Gini to use for time- dependent analyses. It is, however, important to note that for some cases, the relative Gini is mean reverting and the absolute Gini is not. Thus, the results suggest that one should treat each country Gini case by case.

\section{Application to the inequality and growth relationship}

I will now compare the performance of the relative and absolute Gini using an application to the inequality and growth relationship. The relationship between inequality and growth has been intensively investigated (Banerjee and Duflo (2003), Herzer and Vollmer (2012)) and the findings are

\footnotetext{
${ }^{6}$ This means that the effect of a unit shock on the level of the series after $N$ periods converges to zero at infinity, i.e. $\lim _{N \rightarrow \infty} c_{N}=0$.

${ }^{7} \mathrm{I}$ also used the Robinson (1995) multivariate semi-parametric method but the results were often unsatisfactory due to the number of years available.
} 
not conclusive. All empirical analyses investigating the inequality-growth relationship have used the relative Gini. Some studies reveal a positive relationship, some a negative relationship, while others none. Until a stable relationship is identified, it is not possible to accurately advise governments on policies on economic growth and inequality. Thus it will be useful to ascertain if a stable relationship results with the absolute Gini. To observe whether the absolute Gini presents itself as a better candidate compared with the relative Gini for time dependent analyses, I estimate a standard panel regression model that is used in Banerjee and Duflo (B\&D) (2003) and many other papers, with two sets of control variables. To increase the number of countries WIID version (2.2) is used which gives us 45 countries. The B\&D (2003) regressions are estimated with two sets of controls ${ }^{8}$, inspired by the political economy mechanisms as discussed in Perotti (1993) and macro-political economy mechanisms proposed by Barro (1992). The model estimated in this paper is:

$$
g r_{i t}=\alpha+\beta G i n i_{i t}+\mathbf{Z}_{i t} \gamma+e_{i t}
$$

where $g r_{i t}$ is the growth rate of country $i$ in year $t, G i n i_{i t}$ is the inequality measure in country $i$ in year $t, \mathbf{Z}_{i t}$ is a vector of controls and $e_{i t}$ is an error term assumed to be normally distributed $N\left(0, \sigma_{i t}\right)$.The models are estimated using four standard panel regression methods: random effects, first differences in growth and inequality, fixed effects and the Arellano and Bond (1992) estimator ${ }^{9}$. The estimates are presented in Table $2^{10}$. For both sets of controls used, and estimation technique, there are more instances of a significant and negative relationship between absolute inequality and growth. There is however no significant relationship between relative Gini and growth. These results suggest that the absolute measure can be a more reliable measure of inequality for time dependent analyses, as suggested by the results in Section 3.

\section{Conclusion}

In this paper I have highlighted several problems of using time trends of Ginis. First, trends of the relative Gini performs quite differently from its absolute version and thus the choice of which one to use depends upon the nature of the analysis involved. Second, I have modelled relative and

\footnotetext{
${ }^{8}$ Controls used by Perotti (1993) are logged GDP at constant 2000 US dollars, investment share of GDP at constant 2000 US dollars, male years in education, female years in education. Controls used by Barro (1992) are logged GDP squared in (t-1), which in our case is 5 years, logged GDP in (t-1), government share of GDP excluding spending on defence and education in (t-1), percentage of workers with secondary education, percentage of workers with tertiary education, logged fertility, rule of law, Spanish/Portugese colony, other colony, investment share of GDP in (t-1). These variables have been downloaded from the World Bank WDI database.

${ }^{9}$ I have not presented the Blundell-Bond GMM estimates as the empirical literature on inequality and growth has not used it widely. The results however are similar.

${ }^{10}$ In Table 2 I use 2 types of relative Gini variables: Gini as obtained directly from the database, and Gini, filled, where the missing gaps have been filled via linear interpolation. Absolute Gini is the variable directly from the dataset. Absolute Gini, estimated, are own estimates using Gini, filled, and constant 2000 US dollars, and Absolute Gini, estimated PPP, are estimated using constant 2000 PPP-adjusted dollars.
} 
absolute Ginis as a fractionally integrated process to observe their trend properties. I find that each country's relative Gini has a different model compared to its absolute version and that there are more mean-reverting absolute Ginis than relative. This suggests that the absolute Gini (being closer to stationarity) are a better choice for time dependent analyses. To further test for this, I run several panel regression models estimating the inequality and growth relationship as an application, and I find a stable negative relationship between absolute Gini and growth, but not with the relative Gini.

The analysis suggests that one should use relative Ginis with caution and that the absolute Gini may be more suited for time dependent analyses. It may also be one of the underlying reasons for inconclusive results with estimating the inequality and growth relationship, for which further research is required.

\section{References}

[1] Atkinson, A.B., and A. Brandolini (2004). Global world inequality: absolute, relative or intermediate? mimeo.

[2] Banerjee, A and E. Duflo (2003). Inequality and growth: what can the data say? Journal of Economic Growth, 8, 267-299.

[3] Bosmans, K., K.Decanq and A. Decoster (2014). The relativity of decreasing inequality between countries, Economica, 81, 276-292.

[4] Durlauf, S. N., P. A. Johnson, and J. R. W. Temple (2009). The econometrics of convergence. In Terence C. Mills and Kerry Patterson (eds.) Palgrave Handbook of Econometrics, Volume 2: Applied Econometrics. Palgrave Macmillan, June.

[5] Geweke, J. and S. Porter-Hudak (1983). The estimation and application of long memory time series models. Journal of Time Series Analysis 4, 221-238.

[6] Henry, M. and P. Zaffaroni (2002). The long range dependence paradigm for Macroeconomics and Finance, in Long range dependence: Theory and applications, P. Doukhan, G. Oppenheim and M. Taqqu (ed).Birkhäuser, Boston.

[7] Herzer, D. and S. Vollmer (2012). Inequality and growth: evidence from panel cointegration, Journal of Economic Inequality, 10, 489-503.

[8] Mello, M (2011), Stochastic convergence across US States, Macroeconomic Dynamics, 15, 2011, $160-183$.

[9] Michelacci, C., and P. Zaffaroni (2000). (Fractional) beta convergence, Journal of Monetary Economics, 45, 129-153. 
[10] Nunes, L. C., C. M. Kuan and P. Newbold (1995), Spurious breaks, Econometric Theory, 11, 736-749.

[11] Perotti, R (1996): Growth, income distribution and democracy, Journal of Economic growth, 1, 149-187.

[12] Robinson, P. (1995). Log-periodogram regression of time series with long-range dependence. Annals of Statistics 23, 1048-1072.

[13] United Nations University (2015). UNU-WIDER WIID database V 3.3 and V 2.2. 


\begin{tabular}{|c|c|c|c|c|c|c|c|c|}
\hline Country Name & $\begin{array}{l}\text { Sample for } \\
\text { relative Gini }\end{array}$ & $\begin{array}{l}\text { Number of } \\
\text { actual obs., } \\
\text { relative Gini }\end{array}$ & $\begin{array}{l}\text { Sample for } \\
\text { absolute } \\
\text { Gini }\end{array}$ & $\begin{array}{c}\text { Number of } \\
\text { actual obs., } \\
\text { absolute } \\
\text { Gini }\end{array}$ & $\begin{array}{c}\text { dGPH, } \\
\text { relative Gini } \\
\text { (Power }=.5 \text { ) }\end{array}$ & $\begin{array}{c}\text { dGPH, } \\
\text { absolute } \\
\text { Gini (Power } \\
=.5 \text { ) }\end{array}$ & $\begin{array}{l}\text { Underlying variable } \\
\text { for Gini estimation }\end{array}$ & $\begin{array}{c}\text { Average Gini } \\
\text { estimate data } \\
\text { quality (1 = } \\
\text { high, } 2= \\
\text { average) }\end{array}$ \\
\hline Argentina & $1991-2011$ & 21 & $1991-2011$ & 21 & $1.30(0.65)$ & $0.64(0.61)$ & Income,Disposable & 1.00 \\
\hline Australia & $1942-2001$ & 60 & $1950-2001$ & 52 & $1.08(0.23)$ & $1.01(0.10)$ & Taxable Income, Gross & 2.00 \\
\hline Bulgaria & $1992-2011$ & 20 & $1992-2011$ & 20 & $1.63(0.38)$ & $1.35(0.16)$ & Income,Disposable & 1.63 \\
\hline Canada & $1980-2011$ & 32 & $1980-2011$ & 32 & $1.03(0.17)$ & $1.31(0.22)$ & Income,Disposable & 1.08 \\
\hline Costa Rica & $1989-2010$ & 22 & $1989-2010$ & 22 & $0.83(1.01)$ & $0.73(0.15)$ & Income,Disposable & 1.00 \\
\hline Czech Republic & $1987-2005$ & 18 & $1991-2005$ & 15 & $1.61(1.31)$ & $0.41(0.41)$ & Earnings, Gross & 1.30 \\
\hline Denmark & $1981-2011$ & 31 & $1981-2011$ & 31 & $0.80(0.57)$ & $0.87(0.55)$ & Income,Disposable & 1.00 \\
\hline El Salvador & $1995-2011$ & 17 & $1995-2011$ & 17 & $1.57(0.01)$ & $0.71(0.41)$ & Income,Disposable & 1.17 \\
\hline Estonia & $1995-2011$ & 17 & $1995-2011$ & 17 & $1.17(0.24)$ & $1.19(0.32)$ & Income,Disposable & 1.04 \\
\hline Finland & $1976-2011$ & 29 & $1976-2011$ & 29 & $1.16(0.11)$ & $1.45(0.28)$ & Income,Disposable & 1.02 \\
\hline France & $1995-2011$ & 17 & $1995-2011$ & 17 & $1.37(0.47)$ & $0.90(0.34)$ & Income, Disposable & 1.02 \\
\hline Germany & $1968-2011$ & 35 & $1968-2011$ & 35 & $1.39(0.48)$ & $0.92(0.14)$ & Income,Disposable & 1.10 \\
\hline Hungary & $1991-2011$ & 21 & $1991-2011$ & 21 & $0.12(0.66)$ & $1.16(0.34)$ & Income,Disposable & 1.02 \\
\hline India & $1951-2010$ & 33 & $1951-2010$ & 33 & $1.20(0.22)$ & $0.93(0.08)$ & Consumption & 1.97 \\
\hline Italy & $1967-2011$ & 34 & $1967-2011$ & 34 & $1.01(0.19)$ & $0.97(0.18)$ & Income,Disposable & 1.52 \\
\hline Japan & $1962-1997$ & 25 & $1962-1997$ & 25 & $0.85(0.42)$ & $0.84(0.15)$ & Income, Gross & 2.00 \\
\hline Kyrgyzstan & $1992-2006$ & 15 & $1992-2006$ & 15 & $1.00(0.58)$ & $0.76(0.23)$ & Earnings, Gross & 2.00 \\
\hline Lithuania & $1994-2011$ & 18 & $1994-2011$ & 18 & $0.30(0.27)$ & $1.24(0.29)$ & Income,Disposable & 1.17 \\
\hline Macedonia, Fyr & $1990-2008$ & 19 & $1990-2008$ & 19 & $0.32(0.37)$ & $1.05(0.35)$ & Earnings, Net & 2.00 \\
\hline Netherlands & $1987-2011$ & 25 & $1987-2011$ & 25 & $0.35(1.27)$ & $1.41(0.48)$ & Income,Disposable & 1.00 \\
\hline Norway & $1984-2011$ & 28 & $1984-2011$ & 28 & $0.78(0.41)$ & $1.59(0.52)$ & Income,Disposable & 1.18 \\
\hline Poland & $1983-2011$ & 28 & $1983-2011$ & 28 & $1.37(0.41)$ & $1.01(0.14)$ & Income,Disposable & 1.30 \\
\hline Romania & $1989-2011$ & 23 & $1989-2011$ & 23 & $1.74(0.55)$ & $1.77(0.63)$ & Income,Disposable & 1.28 \\
\hline Slovak Republic & $1996-2011$ & 16 & $1996-2011$ & 16 & $0.78(0.36)$ & $1.10(0.34)$ & Income,Disposable & 1.56 \\
\hline Slovenia & $1991-2011$ & 21 & $1991-2011$ & 21 & $1.18(0.20)$ & $1.10(0.13)$ & Income,Disposable & 1.24 \\
\hline Spain & $1995-2011$ & 17 & $1995-2011$ & 17 & $1.09(0.63)$ & $0.98(0.18)$ & Income,Disposable & 1.03 \\
\hline Sweden & $1975-2011$ & 37 & $1975-2011$ & 37 & $0.79(0.42)$ & $1.06(0.18)$ & Income,Disposable & 1.07 \\
\hline Taiwan & $1976-2010$ & 29 & $1976-2010$ & 29 & $1.59(0.49)$ & $1.21(0.09)$ & Income,Disposable & 1.03 \\
\hline United Kingdom & $1961-2011$ & 51 & $1961-2011$ & 51 & $0.84(0.55)$ & $1.19(0.12)$ & Income,Disposable & 1.01 \\
\hline United States & $1944-2004$ & 59 & $1950-2004$ & 54 & $1.26(0.31)$ & $1.00(0.04)$ & Monetary Income, Gross & 1.00 \\
\hline
\end{tabular}

Notes: Figures in parentheses are standard errors

Table 1. Fractionalizing Differencing Parameters for Relative and Absolute Gini processes 
Perotti Controls

\begin{tabular}{|c|c|c|c|c|c|c|c|c|}
\hline & $\mathbf{R E}$ & FD & FE & AB & RE & FD & FE & AB \\
\hline Gini & 0.021 & -0.10168 & -0.00704 & -0.131 & 0.069 & 0.009 & 0.061 & 0.286 \\
\hline Standard error & & 0.035 & 0.095 & 0.073 & & 0.057 & 0.124 & 0.101 \\
\hline $\mathrm{N}$ & 212 & 155 & 212 & 140 & 150 & 104 & 150 & 45 \\
\hline Gini, filled & 0.000 & -0.109 & -0.007 & 0.114 & 0.069 & 0.033 & 0.033 & 0.013 \\
\hline Standard error & 0.032 & 0.105 & 0.07 & 0.235 & 0.065 & 0.095 & 0.095 & 0.214 \\
\hline $\mathrm{N}$ & 292 & 247 & 292 & 206 & 191 & 151 & 191 & 78 \\
\hline Absolute Gini & $0.000^{* *}$ & $-9.50 \mathrm{E}-10^{\star \star \star}$ & $6.92 E-16$ & $-5.30 \mathrm{E}-10^{\star \star *}$ & 7.09E-17 & 1.10E-06 & $4.71 \mathrm{E}-07$ & $-4.29 \mathrm{E}-10^{\star \star *}$ \\
\hline Standard error & $3.53 E-16$ & $3.52 E-10$ & $4.50 \mathrm{E}-16$ & 1.20E-10 & $-6.81 E-16$ & $1.44 \mathrm{E}-05$ & 6.30E-06 & $1.11 \mathrm{E}-10$ \\
\hline $\mathrm{N}$ & 66 & 48 & 66 & 43 & 38 & 26 & 38 & 22 \\
\hline \multicolumn{9}{|l|}{ Absolute Gini, } \\
\hline estimated & $-0.000^{* \star}$ & $-8.30 \mathrm{E}-07$ & $-2.35 E-08$ & 5.17E-06 & $2.44 \mathrm{E}-07$ & $9.75 \mathrm{E}-06$ & 3.80E-06 & 5.53E-06 \\
\hline Standard error & $1.50 \mathrm{E}-06$ & $6.71 E-06$ & 2.60E-06 & 5.92E-06 & 2.92E-06 & 1.05E-05 & 5.41E-06 & 9.29E-06 \\
\hline $\mathrm{N}$ & 292 & 247 & 292 & 206 & 191 & 150 & 191 & 78 \\
\hline \multicolumn{9}{|l|}{ Absolute Gini, } \\
\hline estimated PPP & $-0.000^{\star \star *}$ & $-8.50 E-06^{\star \star *}$ & $-2.58 E-06^{\star}$ & $4.60 \mathrm{E}-06$ & $-3.11 \mathrm{E}-06^{\star *}$ & $-7.20 \mathrm{E}-06^{\star \star \star}$ & $-4.05 E-06^{\star *}$ & 8.82E-06 \\
\hline Standard error & $1.01 E-06$ & 2.25E-06 & 1.40E-06 & 3.60E-06 & 1.56E-06 & $2.17 E-06$ & 2.00E-06 & $1.14 \mathrm{E}-05$ \\
\hline $\mathrm{N}$ & 292 & 247 & 292 & 206 & 191 & 151 & 191 & 78 \\
\hline
\end{tabular}

Notes: ${ }^{*} 10 \%$ level of significance, ${ }^{* *} 5 \%$ level of significance, ${ }^{* *} 1 \%$ level of significance. See footnote 7 and 9 for controls and variable definitions.

Table 2: Panel regressions: dependent variable, growth 